\title{
Stability and change in burnout: A 10 -year follow-up study among primary care physicians
}

\author{
Wilmar B. Schaufeli ${ }^{*}$, Gerard H. Maassen ${ }^{2}$, Arnold B. Bakker ${ }^{3}$ \\ and Herman J. Sixma ${ }^{4}$ \\ 'Department of Social and Organizational Psychology and Research Institute \\ Psychology \& Health, Utrecht University, The Netherlands \\ 2Department of Methodology \& Statistics, Utrecht University, \\ The Netherlands \\ ${ }^{3}$ Department of Work and Organizational Psychology, Erasmus University \\ Rotterdam, The Netherlands \\ ${ }^{4}$ Netherlands Institute for Health Services Research, Utrecht, The Netherlands
}

\begin{abstract}
The aim of the present study is (I) to investigate the impact of patient demands on primary care physicians' burnout and (2) to examine the stability and change of burnout across time. Participants were drawn from the official Dutch registration system for primary health care, and longitudinal panel data $(n=165)$ from three waves with a 5 -year time interval were used. They filled in the Maslach Burnout Inventory (MBI) and a validated scale for the assessment of patient demands. The results of various stability and change models that were tested using structural equation modelling (SEM) indicated that demanding patient contacts lead to increased burnout among physicians. In addition, the findings suggested that about one quarter of the variance in physician's actual burnout levels across one decade is accounted for by a stable component, whereas about three quarters is accounted for by a change component. Hence, physician burnout seems to be a rather chronic condition that may be aggravated by exposure to demanding patients.
\end{abstract}

Burnout is quite prevalent in health care professionals such as primary care physicians. For instance, a recent study among 1,393 family doctors from 12 European countries concluded that 'Burnout seems to be a common problem in family doctors across Europe, with high levels apparently affecting two-thirds of respondents in this study' (Soler et al., 2008; p. 250). This agrees with the conclusion of a review of articles that were published between 2000 and 2006; 'We may conclude from the results that GPs (General Practitioners: the authors) appear to be particularly susceptible to burnout' (Houkes, Winants, \& Twellaar, 2008; p. 251).

* Correspondence should be addressed to Wilmar B. Schaufeli, PhD, Department of Psychology, Utrecht University, P.O. Box 80. I 40, 3508 TC Utrecht, The Netherlands (e-mail: w.schaufeli@uu.nl). 
A major issue is how burnout develops over time. As we will see below, it seems that burnout is quite stable, at least across time periods up to about 3 years. Studies that take a life-span perspective on burnout by covering longer time frames of, say, one decade or more like the current investigation, are virtually lacking. Knowledge about the longterm stability of burnout is important because life-span approaches such as the selective optimization with compensation model (Baltes \& Baltes, 1990) and the motivational theory of life-span development (Heckhausen, Worsch, \& Schulz, 2010) assume that well-being, satisfaction and motivation - all relevant in the job context - change in the course of a person's life span. Alternatively, scholars in the field of behavioural genetics maintain that subjective well-being is very stable across the life span. For instance, based on a twin study, Lykken and Tellegen (1996) estimated that $80 \%$ of the long-term stable variance in subjective well-being is heritable. This leads them to the somewhat gloomy conclusion that ' . . . trying to be happier [may be] as futile as trying to be taller' (p. 189). Recent psychophysiological (Tops et al., 2006) and electroencephalographical (EEG) research (Van Luijtelaar, Verbaak, van den Bunbt, Keijsers, \& Arns, 2010) suggests a psychobiological basis of burnout, which also would be compatible with the chronic - and possibly heritable and psychobiological - nature of burnout (see below).

Of course, because of complex gene-environment interactions, the developmental and hereditary perspectives are not mutually exclusive (Tabery, 2007). Therefore, an accurate estimation of the long-term stability of burnout, which still stands out, would contribute to the debate between advocates of the life-span approach versus those of the heritability approach. So, the first aim of our study is to assess the stability of burnout across a 10-year period in a representative sample of Dutch primary health care physicians - or General Practitioners (GPs) as they are called in the United Kingdom and Australia. The current study extends the previous one of Bakker, Schaufeli, Sixma, et al. (2000) by including an additional third wave after 5 years. This allows the use of a sophisticated, statistical stability, and change model (Ormel \& Schaufeli, 1991; see below) that estimates the proportions of variance in burnout that can be attributed to a stable and to a variable component, respectively. Since the study of Bakker, Schaufeli, Sixma, et al. (2000) included only two waves, these stable and variable components could not be estimated separately (Cole, Martin, \& Steiger, 2005) so that the stability of burnout was not assessed.

In addition, the current study aims to assess the impact of patient demands on physician's burnout. As will be shown below, GPs are often involved in stressful and emotionally charged interactions with patients and their families. Although there is abundant research that shows a positive association between experienced patient demands and physician's burnout, there is only one longitudinal study that showed that demanding patient contacts of GPs initiate the burnout process, instead of the other way around (Bakker, Schaufeli, Sixma, et al., 2000). However, since the stable and variable components of burnout (and patient demands) were not separated in the latter study, it cannot be ruled out that this might have blurred the results. Hence, the second purpose of our study is to examine the causal relationship between patient demands and burnout in GPs, using a stability and change model - not only for burnout but also for patient demands. That is, patient demands are also assumed to have a stable as well as a change component that can be distinguished from each other. In other words, compared to the study of Bakker, Schaufeli, Sixma, et al. (2000), the current study covers a time period that is twice as long and analyses the data from an essentially different perspective, that is, the stability and change model. 


\section{Burnout among general practitioners}

The three key elements of burnout among physicians are emotional exhaustion (i.e., the depletion or draining of mental energy or resources), depersonalization (i.e., a callous, negative, and cynical attitude towards patients), and a lack of personal accomplishment (i.e., the tendency to evaluate one's work with patients negatively). Although different conceptualizations of burnout exist (Maslach, Leiter, \& Schaufeli, 2008), this definition and the corresponding operationalization in the form of the Maslach Burnout Inventory (MBI; Maslach, Jackson, \& Leiter, 1996) is used most often in research, also among physicians (Schaufeli, 2007). Burnout is identified as a problem for specialist and generalist physicians alike that may have serious consequences, not only for the doctors involved and their families, but also for their patients and the health care system at large, for instance, because of medical errors and replacement costs (Prins et al., 2009; Shanafelt, Bradley, Wipf, \& Back, 2002; Spickard, Gabbe, \& Christensen, 2002).

Typically, when compared with other physicians, primary health care physicians report relatively high burnout rates. This is illustrated by a recent meta-analysis that covered 110 studies and concluded that primary health care physicians exhibit significantly higher burnout scores compared to medical specialists, residents, medical students, and other practicing physicians (Mauthe, Boudreau, \& Lalumière, 2009). Moreover, a Dutch study (Bakker, Schaufeli, \& Van Dierendonck, 2000) that includes 13,463 employees from 29 different professions and that uses clinically validated cut-off points for burnout (Schaufeli, Bakker, Schaap, Kladler, \& Hoogduin, 2001). This study ranks occupational physicians, primary health care physicians, and midwives at the top of the list with $11.3 \%, 8.2 \%$, and $7.8 \%$ suffering from severe burnout, respectively. That means that that their burnout scores are comparable with those who received psychological treatment for their burnout problems.

\section{Burnout across time}

The typical stabilities across a 1-year time interval for the core components of burnout are .60 and .50 for emotional exhaustion and depersonalization, respectively (for overviews see Schaufeli \& Enzmann, 1998; Taris, Le Blanc, Schaufeli, \& Schreurs, 2005). Even after 8 years, a stability coefficient of .62 was observed for emotional exhaustion (Toppinnen-Tanner, Kalimo, \& Mutanen, 2002). A recent 2-year follow-up study of Dutch primary care physicians revealed stability coefficients of .70 and .60 for exhaustion and depersonalization, respectively (Houkes et al., 2008). Stability of burnout scores is to be expected, though, because burnout is defined as a chronic rather than a transient condition (Maslach, Schaufeli, \& Leiter, 2001). Consistent with this view, a recent prospective epidemiological study among over 12,000 Dutch employees showed that after 3 years only $34 \%$ had recovered from their severe burnout levels at baseline (Leone, Huibers, Knottnerus, \& Kant, 2008). The reason for the relatively high stability across time may be that burnout is related with personality traits such as neuroticism that may act as vulnerability factors, also in physicians (McManus, Keeling, \& Paice, 2004). In addition, as a rule, most work environments do not change dramatically over time (Leana \& Barry, 2000).

This high level of stability poses a problem in longitudinal research because there is not enough 'room' left for independent variables, such as patient demands, to have a significant impact (Cole et al., 2005). This problem is sometimes 'solved' by not taking into account previous baseline levels of burnout. For instance, McManus, Winder, and Gordon (2002) investigated normal and reversed causal relationships between stress and 
burnout among 331 UK physicians using a 3-year longitudinal design, but they did not control for baseline scores in their structural equation models. Hence, it cannot be ruled out that the reported longitudinal relationships would disappear when burnout scores at baseline would have been taken into account.

It follows that in order to properly understand the relationship between patient demands and chronic levels of burnout, the stability of burnout across time has to be considered. By stability, we mean the consistency of between-individual differences across time. High stability suggests that physicians who score high on burnout (relative to their peers) at one point in time continue to do so at subsequent points in time. And conversely, physicians who score low continue to score low.

\section{Patient demands}

In her overview of sources of work stress of primary health care physicians, Winefield (2003) distinguishes between stressors related to the interactions with patients (e.g., confrontation with suffering, demanding patients), non-patient stressors (e.g., familywork conflict, intimidating behaviour of colleagues), and organizational stressors (e.g., paperwork, decreasing professional autonomy).

It appears that for primary health care physicians, interactions with patients are particularly prevalent and stressful. For instance, Hobbs (1994) found among almost 1,100 British GP's that no less than $63 \%$ had suffered form some degree of patient aggression in the previous 12 months. Furthermore, Rout, Cooper, and Rout (1996) studied over 40 potential stressors in a random sample of 414 British GP's and found that, after emergency and night calls, dealing with problem patients was the third most frequently mentioned stressor, causing 'extreme stress'. A similar study in a Canadian GP sample showed that, after time pressure, dealing with problem patients was experienced as second most stressful (Rout \& Rout, 1997). Finally, a national Swiss study among primary care physicians found that of the 19 stressors investigated, high patient expectations ranked among the most stressful experiences after organizational stressors such as changes in the health care system and paperwork (Goebring et al., 2005).

Because of the stressful nature of patient demands, it is likely that these might be detrimental. Indeed, it is consistently found that patient demands are positively related to primary health care physicians' health and well-being, including burnout (e.g., Bargellini et al., 2000; Goebring et al., 2005; Myerson, 1991; Rout et al., 1996; for an overview, see Schaufeli, 2007). This agrees with the overwhelming evidence that testifies that burnout results from quantitative job demands (Halbesleben \& Buckley, 2004; Maslach et al., 2001; Schaufeli \& Enzmann, 1998). However, the causal direction of the relationship between patient demands and burnout is not entirely clear. Although from a traditional job stress perspective, patient demands are expected to produce burnout because they drain physician's energy (Schaufeli \& Enzmann, 1998), a reversed causal relationship has been suggested as well. Recently, such reversed (and reciprocal) causation effects have been found in occupational health psychology studies (e.g., de Lange, Taris, Kompier, Houtman, \& Bongers, 2004). An illustration of reversed causation is found in the 'physician-patient cycle model' of Williams, Savage, and Linzer (2006). This model assumes that, in addition to the normal causal path, physician's burnout increases patient demands via the deterioration of the doctor-patient relationship and patient's dissatisfaction with it. Their model seems to be supported by some empirical findings; for instance, burned-out physicians have unhappy patients who do not trust them (Keating et al., 2002), and do not follow their medical advice (DiMatteo, et al., 1993). In addition, 
Shirom, Nirel, and Vinokur (2006) found among medical specialists that burnout mediates the relationship between work overload and lack of autonomy on the one hand, and quality of patient care at the other hand. Consistent with the physician-patient cycle model, Bakker, Schaufeli, Sixma, et al. (2000) found that physicians who score high on depersonalization - and who treat their patients in a callous and impersonal manner are likely to experience more patient demands 5 years later. In other words, burnout (depersonalization) leads to a further deterioration of the doctor-patient relationship. However, a rigorous test of the causal direction of the patient demands - burnout relationship still stands out.

\section{The present study}

Various statistical models have been developed to estimate the proportions of variance in health or well-being that may be attributed to stable versus occasion factors (Cole et al., 2005). Conceptually, these models are based on the dynamic equilibrium model of Heady and Wearing (1989) that assumes that each person has a stable and characteristic symptom level that is determined by such factors as personality traits, genetic predisposition, or enduring environmental conditions (e.g., social economic status, stable work environment). In addition, the model assumes that current symptom levels are influenced by environmental change agents that act to deflect symptom levels from their stable, characteristic level. Finally, it is assumed that adaptive mechanisms tend to neutralize these effects of change agents by restoring the characteristic symptom level. Hence, the advantage of our stability and change model (see below) as compared to more traditional approaches such as cross-lagged effect panel analyses is, that dynamic equilibrium processes can be modelled. This is particularly important here because life-span approaches such as the selective optimization with compensation model (Baltes \& Baltes, 1990) and the motivational theory of life-span development (Heckhausen et al., 2010) suggest person-environment transactions that are dynamic in nature.

Various studies, using multi-wave statistical stability and change models, have shown that roughly between one half and two-thirds of the variance in current depression or distress levels can be attributed to a stability factor, whereas between half and one-third of the variance may be attributed by external change agents (Cole, 2006; Duncan-Jones, Fergusson, Ormel, \& Horwood, 1990; Gorgievski-Duijvesteijn, Bakker, Schaufeli, \& Van der Heijden, 2005; Ormel \& Schaufeli, 1991).

The current study has two objectives: (1) to determine the nature and direction of the causal effect of patient demands on burnout; (2) to investigate the stability of burnout across a 10-year period, using three waves with a 5-year time interval. This relatively long time lag has been chosen because burnout is defined as a reaction to chronic job stress (Maslach et al., 2001), but almost all longitudinal studies have included relatively short time intervals (much shorter than one decade). Both objectives are met simultaneously by testing a structural equation model that partitions the variance of the observed variables (burnout and patient demands) into a stable component, which - by definition - does not change over time, and a remaining change component (see below). Moreover, the model assumes that the change component of patient demands impacts the change component of burnout (see Figure 1). This type of model aims at answering questions that cannot be investigated by, for instance, cross-lagged panel designs that calculate the strength of the relations between an aggregation of stable and variable components of patient demands on the one hand, and aggregated stable and variable components of burnout symptoms on the other hand. 


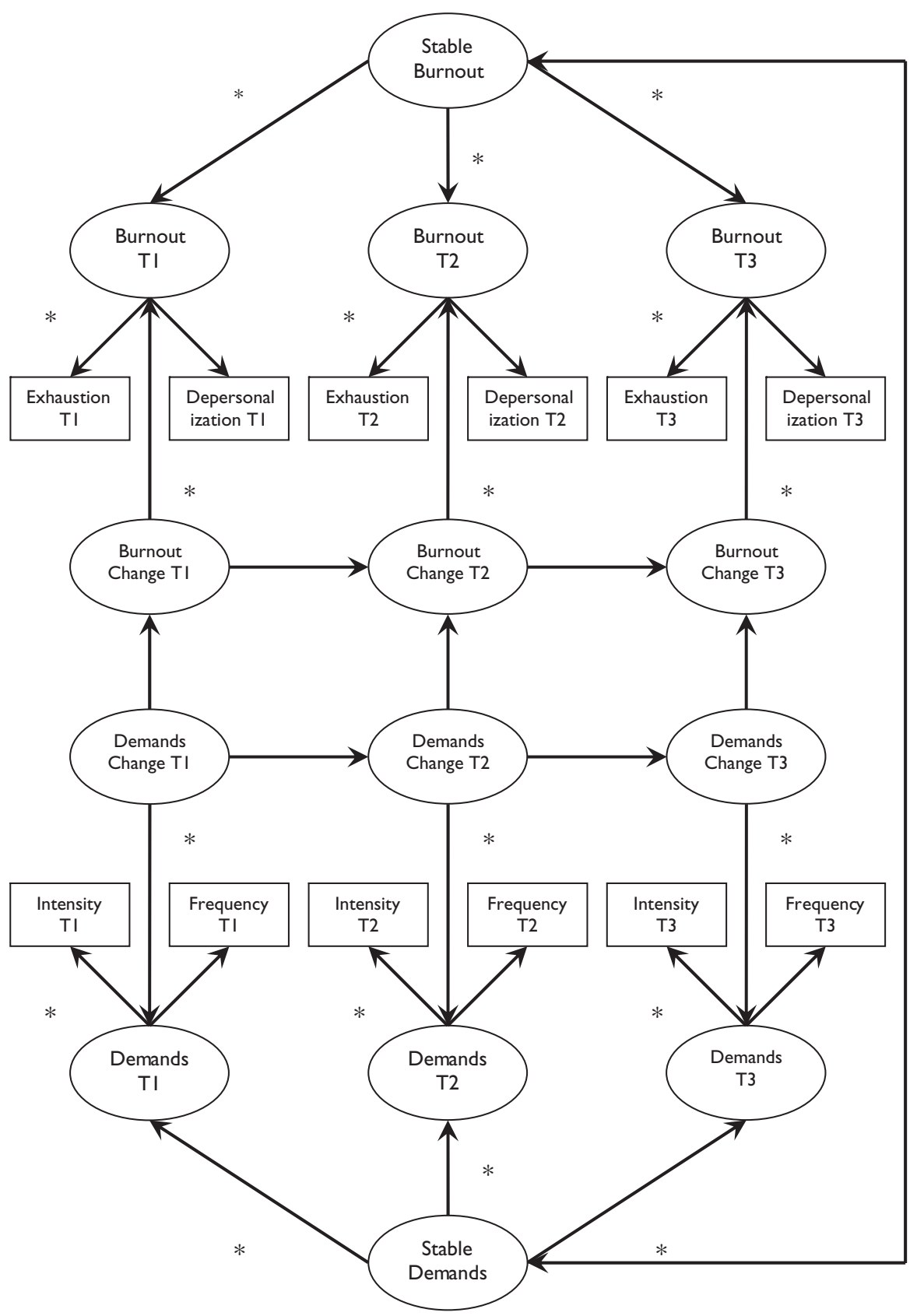

Figure I. The stability and change research model.

Note. *Constrained to I.0.

\section{The research model}

The model tested is an extension of the stability and change model of Ormel and Schaufeli (1991) that is based on the principles of the conceptual dynamic equilibrium model of Heady and Wearing (1989). This stability and change model has also been dubbed latent 
trait-state-occasion (TSO) model (Cole et al., 2005). The initial (full) model is depicted in Figure 1.

In this model, burnout is regarded as a latent construct measured at three time points (T1-T3) by two observed variables, emotional exhaustion, and depersonalization. The physician's actual level of burnout is assumed to be the sum of two uncorrelated components: a component reflecting the stability of burnout over time and a component reflecting occasional changes. The change components at Time 2 and Time 3 are assumed to be influenced by the change component of the previous assessments. This means that variance of the observed burnout scores (i.e., emotional exhaustion and depersonalization) is partitioned into a stable component that - by definition - does not change across time, and a change component that - by definition does change across time.

The initial model can be seen as a double stability-change model, in the sense that the conceptualization of burnout is mirrored by the conceptualization of patient demands. Patient demands are regarded as a latent construct measured at the same three time points by two observed variables: the frequency and the intensity of the demands. Again, the actual patient demands are seen as the sum of two uncorrelated components: a stable component over time and a component reflecting the occasional change. And likewise the change component at the second and at the third occasions is assumed to be influenced by the change components of the previous occasions. The burnout part of the model is linked with the demands part by assuming (1) that the stable components of burnout and demands are correlated and (2) that the change components of burnout are influenced by the change components of patient demands. The former reflects the notion that stable burnout as well as stable patient demands might be related to either personality traits or a stable work environment. For instance, neuroticism has been identified as a vulnerability factor for burnout in physicians (McManus et al., 2004) while at simultaneously having a negative impact on the perception of job demands (Dollard \& De Jonge, 2003). The latter agrees with our model that assumes that patient demands influence physicians burnout levels.

\section{Method}

\section{Participants and procedure}

Participants were drawn from the official registration system at The Netherlands Institute for Primary Health Care. This system, encompassing virtually all primary health care physicians established in The Netherlands, allowed us to draw a national exemplary sample, whereby gender, age, urbanization (i.e., countryside, urbanized countryside, small cites over 5,000 inhabitants, large cities over 500,000 inhabitants), and practice form (i.e., single, shared, group practice, or health care centre) were taken into account. At Time 1, a random sample of 801 practitioners, drawn from the registration system encompassing 6.470 primary health care physicians, received a mailed questionnaire (response $71 \%, N=567$ ). After informed consent for a follow-up study and deleting inconsistent data records after checking with the registration system, 462 physicians remained (58\%). This group was administratively followed twice across a decade. At Time 2, after 5 years, 55 physicians (12\%) were no longer practicing. The remaining sample of 407 physicians received a second, mailed questionnaire, including similar scales as 5 years before. The response rate for this second wave was $73 \%(N=299)$. Five years later, at Time 3 - and again after deleting inconsistent data records and informed 
consent - a sample of 225 physicians received a third, mailed questionnaire. The final data set, with respondents that participated in all three waves across a 10-year period consisted of 165 primary health care physicians.

In order to determine whether or not attrition might have biased results, we used logistic regression analyses to test whether participation at Time 3 was related to any of the four variables (i.e., frequency and intensity of patient demands, and emotional exhaustion and depersonalization - see below) that were measured at Time 1 (cf. Goodman \& Blum, 1996). Since the analyses did not produce significant terms, we may conclude that the attrition was random. In addition, it appeared that no systematic drop-out had occurred for gender $\left(\chi^{2}=.42, d f=1\right.$, n.s. $)$ and practice form $\left(\chi^{2}=3.63\right.$, $d f=3$, n.s.), whereas physicians from larger cities were slightly overrepresented at $\mathrm{T} 3$ as compared to $\mathrm{T} 1\left(\chi^{2}=8.44, d f=3, p<.05\right)$.

\section{Measures}

Patient demands were assessed using an adapted and validated version (Bakker, Schaufeli, Sixma, et al., 2000) of a scale developed by Mechanic (1970). The scale includes items that describe demanding patient behaviours such as 'A patient who insisted on referral to a consultant although you did not regard the referral as necessary' and 'A patient who has threatened to write to the disciplinary committee to complain about you'. Based on a series of open interviews, four items were added that were deemed important for Dutch primary health physicians (e.g., 'A patient who threatens you physically'). The resulting 14 items were scored on a frequency scale $(1=$ never, $4=$ often $)$ and an intensity scale $(1=$ no burden, $4=$ very burdensome $)$.

Burnout was measured with two scales of the Dutch version (Schaufeli \& Van Dierendonck, 2000) of the MBI (Maslach et al., 1996): emotional exhaustion (e.g., 'I feel emotionally drained from my work') and depersonalization (e.g., 'I feel I treat some of my patients as if they were impersonal objects'). Lack of personal accomplishment was excluded since accumulating empirical evidence indicates that this burnout dimension plays a divergent role as compared to exhaustion and depersonalization (see e.g., Lee \& Ashforth, 1996; Leiter, 1993). Moreover, it appeared that instead of the usual practice to reverse the positively worded accomplishment items, reduced accomplishment is more adequately measured with a scale that consists of negatively worded items (Schaufeli \& Salanova, 2007). Finally, and most importantly, it has been argued on theoretical grounds that exhaustion and mental distancing constitute the core of the burnout syndrome (Demerouti, Bakker, Vardakou, \& Kantas, 2003; Schaufeli \& Taris, 2005). All burnout items were scored on a 7-point rating scale, ranging from (0) 'never' to (6) 'every day'.

\section{Analyses}

Structural equation modelling (SEM) methods as implemented by LISREL (Jöreskog \& Sörbom, 1989) were used to test the fit of the research model. SEM enables testing of models that encompass two elements: (1) the measurement model, which specifies how the latent constructs are indicated by directly observed variables. An appropriate measurement of latent constructs by two or more observed variables generally bears the advantage of 'disattenuating' the relationships from measurement error, which is expressed in 'sharper' values of the parameters. (2) The structural model, which is essentially a path model, that is, a system of regressions equations, where variables may act as independent variable in one relationship as well as dependent variable 
in another. The variables involved in these relationships may be observed, measured variables, or not directly observed latent constructs. Maximum likelihood estimation methods were used and the input for the analysis was the covariance matrix of the scale scores. The goodness-of-fit of the model was evaluated by using absolute fit indices like the $\chi^{2}$ goodness-of-fit statistic, root mean square error of approximation (RMSEA), and standardized root mean square residual (SRMR), as well as relative fit indices such as non-normed fit index (NNFI) and comparative fit index (CFI). For these two relative fit indices, as a rule of thumb, values greater than .95 are considered as indicating a good fit, whereas values smaller than .06 for RMSEA are indicating an acceptable fit (Hu \& Bentler, 1999).

More specifically, exhaustion and frequency at each time point (see Figure 1) are chosen as reference variables for scaling the underlying latent constructs; consequently, their factor loading is set to 1 . The assumption of burnout and demands being the summation of a stable and a change component allows the fixation of the 12 corresponding parameters at 1 . In the figures representing the models that were tested, the parameter values initially fixed at 1 are marked with an asterisk. As described below, more than one step was required to yield a satisfactory and more parsimonious model. In all models, we implemented the assumption of equal covariances between the unicity (including error) components of the three longitudinal assessments of exbaustion, depersonalization, frequency, and intensity, respectively. This is done in order to account for retest effects resulting in higher intercorrelations of identical variables measured at subsequent moments in time as compared to the intercorrelations of nonidentical items (Jöreskog \& Sörbom, 1989, p. 168). For the sake of clarity, the doublesided arrows representing these covariances are omitted in all figures.

\section{Results}

\section{Descriptive statistics}

Table 1 displays the means, standard deviations, correlations, and internal consistencies (Cronbach's $\alpha$ ) of the study variables. As can be seen from Table 1, all values of Cronbach's $\alpha$ exceed the criterion of .70 (Nunnally \& Bernstein, 1994). Stabilities across 5 and 10 years for emotional exhaustion are .66 and .59 , respectively, and for depersonalization .58 and .43 , respectively. Values for patient demands are in the same range with 5- and 10-year stabilities for frequency of .61 and .49, respectively, and for intensity of .57 and .50 , respectively. Correlations of emotional exhaustion and depersonalization with age $(-.03<r<.05,-.07<r<.10$, respectively) and work experience $(-.02<r<.03,-.06<r<.09$, respectively) were non-significant. In addition, levels of burnout did not differ between men and women $\left(-.91<t_{(163)}<.18\right.$ for emotional exhaustion and $1.04<t_{(163)}<1.77$ for depersonalization). Hence, we did not control for these socio-biographical variables in our models.

\section{Model testing}

Step I

We started by testing our initial research model as displayed in Figure 1. In terms of fit indices, the fit between the data and this model was satisfactory $\left(\chi^{2}=36.2, d f=40\right.$, $p=.64, \mathrm{RMSEA}=0, \mathrm{CFI}=\mathrm{NNFI}=1, \mathrm{SRMR}=.039)$. However, there are two reasons to adapt the initial research model. First, the correlations between the parameter estimates gave reason to distrust the stability of the solution, particularly as far as the variance of 


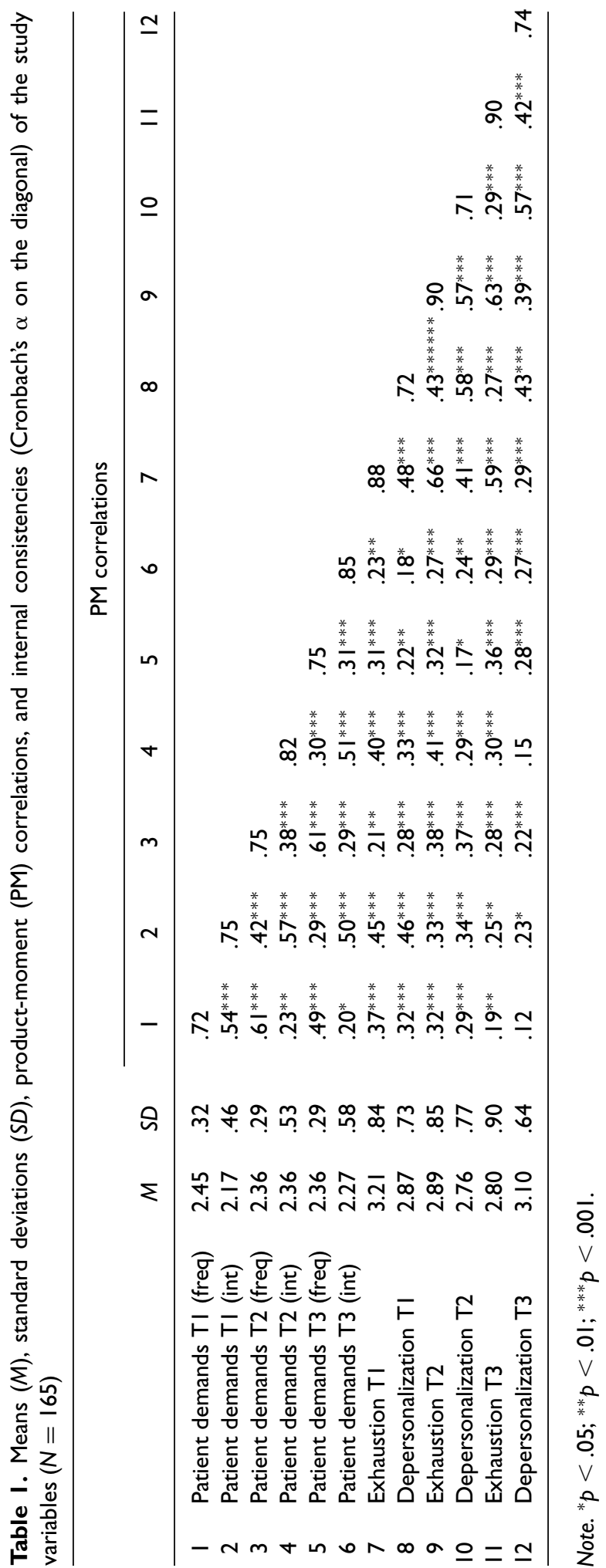


the stable component of demands and its very high correlation $(r=.90)$ with the stable component of burnout is concerned. Second, in the standardized solution, the coefficients of the regression of the change components of patient demands on the actual patient demands were extremely high (.89 and higher). This result would make it plausible to consider the occasional change components of patient demands and the actual demands identical. Hence, in the second step a model that was revised accordingly was tested.

\section{Step 2}

The outcome of step 1 led us to consider a revised model (1) where the latent stable demand construct is discarded, (2) where the actual patient demands and the occasional change components of patient demands are assumed identical, and (3) where - as a consequence - the stability of patient demands is solely expressed in terms of Time 1-Time 2 and Time 2-Time 3 stability coefficients. The revised model and resulting parameter estimations of the completely standardized solution are presented in Figure 2 .

The test of this revised model, too, resulted in satisfactory values of the fit indices: $\left(\chi^{2}=37.5, d f=42, p=.67, \mathrm{RMSEA}=0, \mathrm{CFI}=\mathrm{NNFI}=1, \mathrm{SRMR}=.043\right)$. In our view, this revised model is acceptable. The revised model shows that patient demands at Time 2 and at Time 3 increase physician's burnout at Time 3, while controlling for levels of burnout and demands at previous occasions. Or phrased differently, changes in burnout across time are positively influenced by demanding contacts with patients. The more frequent and intensive these problematic contacts, the more burned out the physicians feel. In addition, it appears that between $23 \%$ and $28 \%$ of the variance of physician's actual burnout levels is accounted for by a stable component, whereas inversely between $72 \%$ and $77 \%$ is accounted for by a change component.

\section{Step 3}

In the final step, we investigated the direction of the relation between burnout and patient demands. To that end, we first tested the initial research model of step 1 but now assuming a bidirectional relationship between the change components of burnout and patient demands. Unfortunately, this model did not yield a convergent solution. Next, the revised model of step 2 was tested, again with a bidirectional relationship instead of patient demands influencing burnout. This yielded an inadmissible solution that implicated a negative variance. Finally, the revised model of step 2 was tested hypothesizing only reversed causation, that is, it was assumed that the change component of burnout influences patient demands, instead of the other way around as assumed in our original model (see Figure 1). This reversed causation model and the resulting parameter estimations of the standardized solution are presented in Figure 3.

The solution fits the data equally well as that of the revised initial model: $\chi^{2}=$ 37.2, $d f=42, p=.68$, RMSEA $=0, \mathrm{CFI}=1, \mathrm{NNFI}=1$, SRMR $=.039$. However, there is a substantive reason to reject this model. Although the revised initial model accounts for the stability and change components in burnout, it seeks to establish the stability of burnout by estimating very high-stability coefficients between the change components of burnout (in connection with very high path coefficients between these change components and the actual burnout symptoms), while at the same time yielding relatively low path coefficients between stable burnout and the actual burnout symptoms (see Table 1). This is of course a substantive contradiction. So taken together, these 


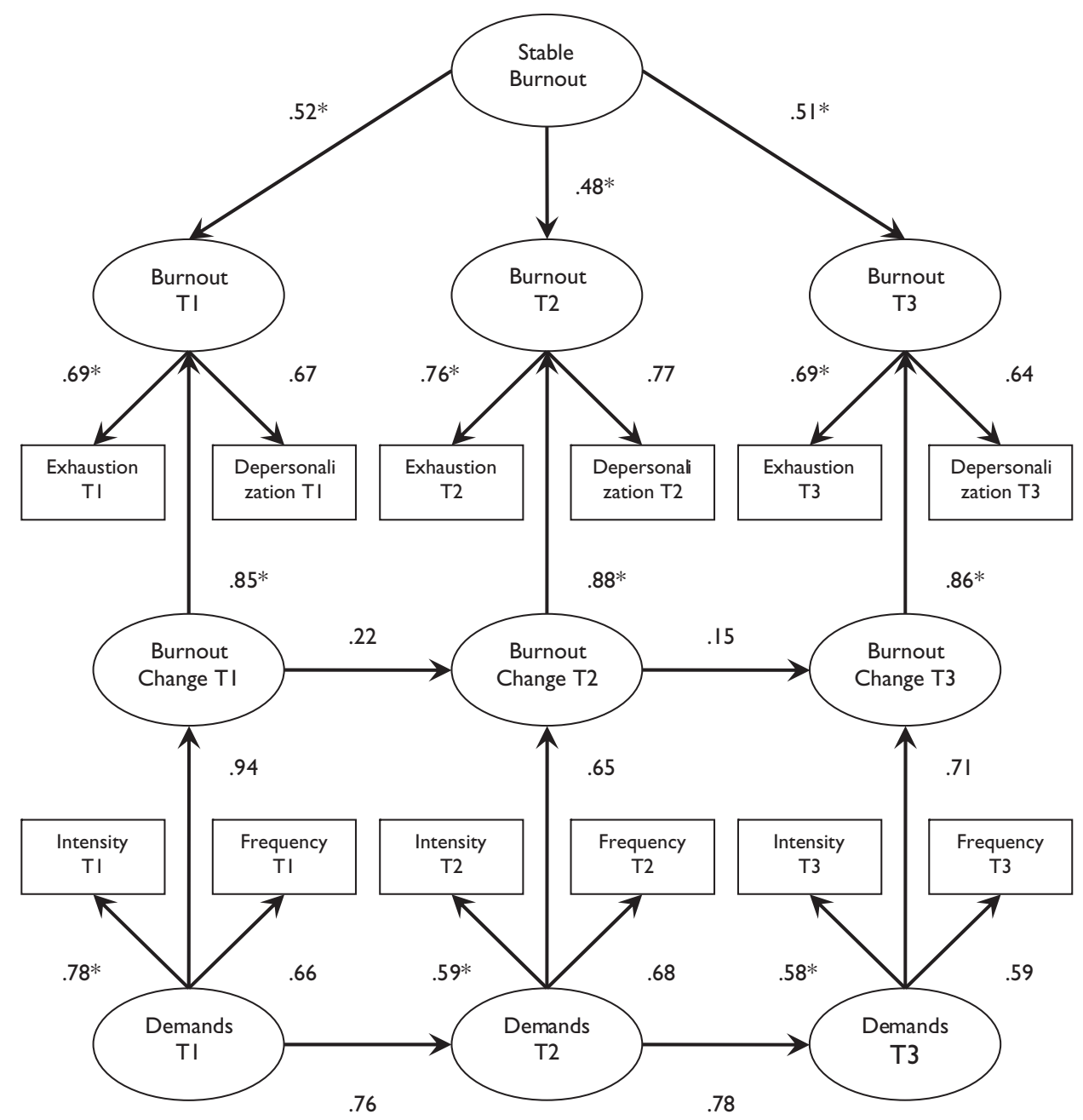

Figure 2. The revised stability and change model (standardized solution; $n=165$ ). Note. ${ }^{*}$ Constrained to I.0.

findings disagree with the established notion that burnout is a rather chronic condition (Leone et al., 2008; Maslach et al., 2001) and hence we conclude that the model depicted in Figure 2 is to be preferred to that of Figure 3.

\section{Discussion}

The first aim of the present study was to determine the nature and direction of the causal effect of patient demands on burnout. After testing various models, the most plausible model assumed that patient demands have a positive impact on physician burnout, rather than the other way around. This finding supports the traditional view that qualitative job stressors - in this case frequent and intensive demanding contacts with patients - can cause burnout. Although abundant empirical evidence exists for this linkage between job stressors and burnout (for reviews see Halbesleben \& Buckley, 2004; Maslach et al., 2001; Schaufeli \& Enzmann, 1998) reversed causation has also been 


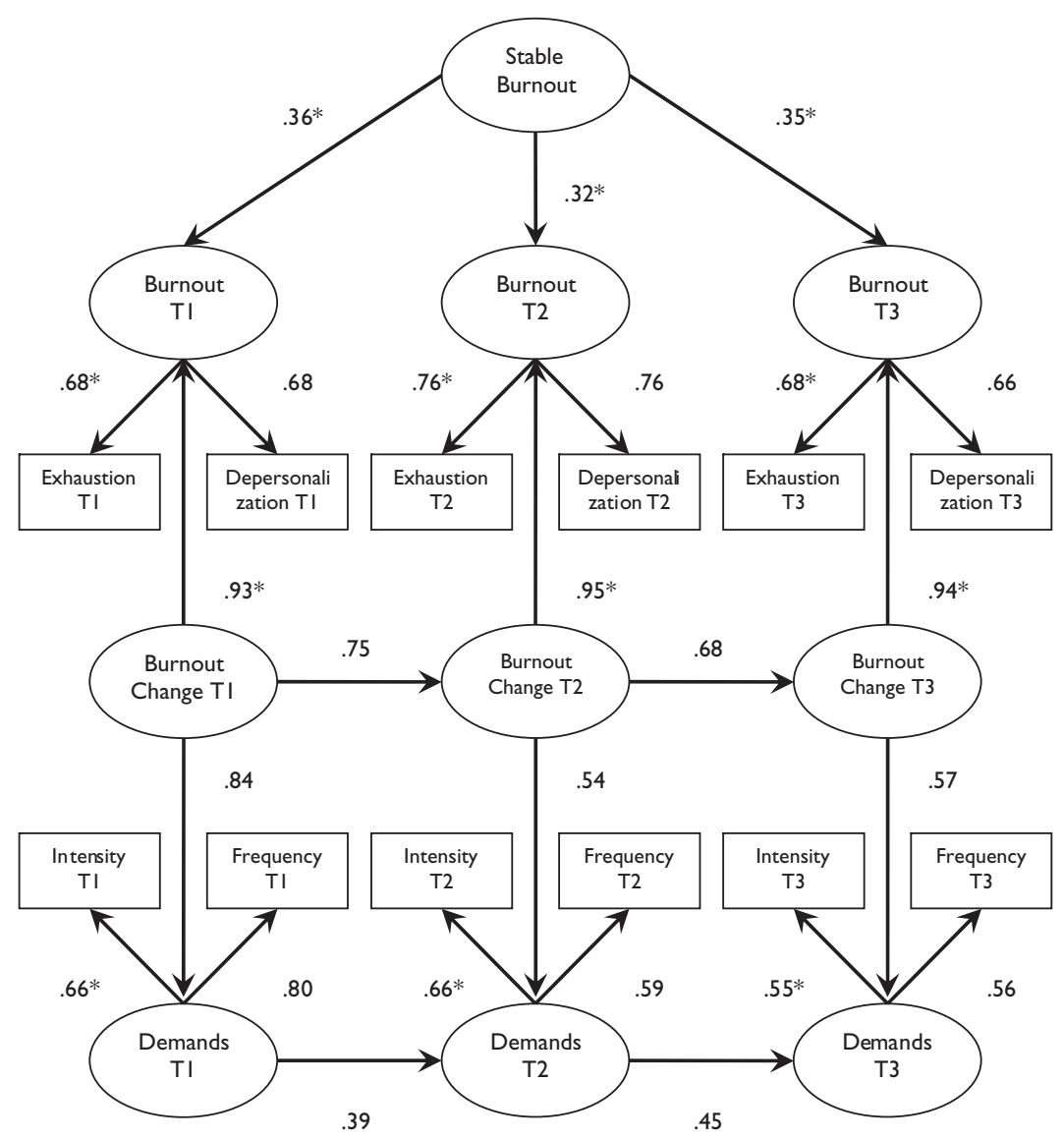

Figure 3. The reversed causation stability and change model (standardized solution; $n=165$ ). Note. *Constrained to I.0.

observed. For instance, De Jonge et al. (2001) reported a positive effect of emotional exhaustion on job demands, and not vice versa. Similar effects were found by Leiter and Durup (1996), who observed a reversed relationship between emotional exhaustion on the one hand, and workload and supervisory support on the other hand. So, there was a good reason to examine reversed causation in our sample. Although the alternative, reversed causation model that assumed that burnout would have a positive impact on the perception of patient demands also fit to the data, it had to be rejected. It was found to be less plausible because essentially it was at odds with the well-established notion that burnout is a chronic condition (Leone et al., 2008; Maslach et al., 2001). The acceptance of the revised research model and the rejection of reversed causation model implies that reversed causation is less likely, and therefore our data do also not support the physician-patient cycle model that postulates that physician's burnout increases patient demands via the deterioration of the doctor-patient relationship (Williams et al., 2006). In fact, a model that assumes a bidirectional relationship between burnout and patient demands would have been the most appropriate model to assess the validity of this cycle model. But unfortunately, the test of a bidirectional model, in this case, failed to converge in a solution. 
Please note that our findings do not indicate that patient demands have a lagged affect on physician's burnout as assessed 5 years later. Rather, our findings suggest that physician's current burnout levels are influenced by the currently experienced patient demands, while controlling for previous levels of burnout and experienced demands, as well as for the stability that is inherent to burnout. We tested a model with lagged effects of patient demands on physician burnout 5 years later, but unfortunately the test failed because the model was not identified. However, according to the dynamic equilibrium model (Heady \& Wearing, 1989), such lagged effects are not very likely to be observed in our data, in the first place. The dynamic equilibrium model assumes (1) that change agents such as patient demands deflect burnout symptoms from their stable, characteristic level and that (2) adaptive mechanisms tend to neutralize these effects so that the characteristic burnout level is restored. The longer the time interval the more likely it is that these adaptive mechanisms can do their job. For instance, doctors might learn to cope more effectively with patient demands so that their supposedly high burnout levels are likely to be diminished at the next follow-up. This would be in line with the selective optimization with compensation model (Baltes \& Baltes, 1990), which assumes that in the course of their (professional) life span, people adapt in a dynamic way by using strategies such as selection (i.e., the limitation of resources, such as time and energy because not all opportunities can be pursued), optimization (i.e., the allocation of resources in order to achieve higher levels of functioning in specific domains), and compensation (i.e., the substitution of resources in case of resource loss so that a satisfactory level of functioning is maintained). For instance, over the past 10 years, physicians might have referred particular patients more systematically (selection), have followed a training in patient communication skills (optimization), or have been engaged in continuing medical education (compensation). Freund and Baltes (1998) showed that selection, optimization, and compensation strategies are positively related to indicators of successful aging (i.e., well-being, positive emotions, and absence of loneliness). Hence, it can be hypothesized that using such dynamic adaptation strategies during one's professional life span may result in a rather stable level of burnout. Future research should uncover this. In order to do so, the time lag should be smaller than 5 years so that the likelihood increases of detecting lagged effects; namely, the longer the time lag, the more likely that the adaptation processes is successful - that is, that the individual returns to his or her set point. For instance, in a longitudinal study on the effect of social stressors at work Dormann and Zapf (2002) found that a model with a time lag of 2 years was superior to that with a longer time lag of 4 years.

The second aim of our study was to investigate the stability of burnout across one decade. Our stability and change model allowed the partitioning of the variance of physician's actual burnout scores into a proportion that may be attributed to a stable and a changing component, respectively. Based on the results of the most plausible model (see Figure 2), it was estimated that between $23 \%$ and $28 \%$ of the variance of physician's burnout levels across a 10-year period may be attributed to a stable component. This is a comparable proportion as that observed by Dormann, Fay, Zapf, and Frese (2006), who used a similar stability and change model that included four waves to estimate the stable and change components of job satisfaction. Depending on the wave, they estimated the proportion of stable variance in job satisfaction between $23 \%$ and $26 \%$. This is much lower than the proportions for depression (Cole, 2006), life satisfaction (Lucas \& Donnelan, 2007), or psychological distress (Duncan-Jones et al., 1990; Gorgievski-Duijvesteijn et al., 2005; Ormel \& Schaufeli, 1991), which are roughly estimated at two-thirds, again by using similar stability and change models. A possible reason of this discrepancy might be that burnout and job satisfaction are both 
work-related, whereas depression and psychological distress are context free. By definition, work-related well-being is more sensitive for environmental influences than contextfree well-being. Therefore, the change component is more salient for work-related wellbeing (burnout and job satisfaction) than for context-free well-being (depression and distress), whereas the reverse is true for the stable component.

And what about the stable component of burnout; how should this be interpreted? Twin studies suggest that about $50 \%$ of the variance in subjective well-being can be attributed to genetic influences (Lykken \& Tellegen, 1996; Nes, Røysamb, Tambs, Harris, \& Reichborn-Kjellerud, 2006). Moreover, these studies estimate that about $80 \%$ of the long-term stable variance of subjective well-being is explained by genetic contributions. This is compatible with the notion of a biologically determined 'set point' of well-being, as assumed in the dynamic equilibrium model (Heady \& Wearing, 1989). Homeostatic forces return the level of well-being to its original level (set point) after the occurrence of pleasant or unpleasant events. Although burnout is not equivalent to subjective wellbeing, it is likely that a similar, biogenetic set point plays a role in explaining its stability over time.

Please note that, contrary to burnout, a stable component does not seem to play a role in patient demands. Although our initial research model assumed that the variance in patient demands could be partitioned in a stable and a change component, (see Figure 1), it appeared that the stable component did not play a significant role. In other words, rather than being influenced by some stable (person or environmental) characteristic, changes in patient demands are influenced by previous changes.

\section{Study limitations and directions for future research}

The unique strengths of the current study are the use of a representative sample of Dutch primary care physicians and the three-wave longitudinal design that spans a rather long period of 10 years. Nevertheless, the present also study has certain limitations. A first limitation is that data are based on self reports, meaning that the magnitudes of the effects that we reported may have been biased due to common method variance or the wish to answer consistently (Conway, 2002). Unfortunately, we cannot test the strength of this type of variance directly. However, Spector (2006) has argued that common method variance is not that troublesome as one might expect in studies such as the current one. He convincingly showed that potentially biasing variables such as social desirability, negative affectivity, and acquiescence (the tendency to agree with items independent of their content) do not systematically inflate correlations between self-reported variables. Nevertheless, in order to avoid common method variance future research on physician burnout should include non-self reports as well, such as peer ratings (Piedmond, McCrae, Riemann, \& Angleiter, 2000) and doctor-patient observations (Epstein, Franks, Fiscella, et al., 2005).

A second limitation, as noted above, is the relatively long time lag of 5 years in which dynamic adaptation processes might have neutralized the negative effects of exposure to demanding patient contacts on burnout. Hence, future research should include multiple, but smaller time lags. An example is the study of Burisch (2002), who assessed burnout, personality, and work experience of student nurses at seven time points over a period of 3 years. Unfortunately, in this study intra-individual change in burnout scores could neither be linked to dispositions, nor to the nurses' work experiences. However, data were not analysed with a stability and change model.

A third limitation is that we can only speculate about the nature of stable component of burnout. Basically, the stability component only reflects the proportion of variance in 
burnout that remains stable across time, and does not reveal the nature of this stability. That stability might be caused by a steady, unchanging environment and/or by personality factors. For instance, using the same stability and change model as in the present study, Ormel and Schaufeli (1991) observed a high-positive correlation of a stable distress component with external locus of control and a high-negative correlation with selfesteem. In order to examine the nature of the stable burnout component, future studies could include personality factors such as neuroticism and agreeableness that are known to be related with burnout, also in physicians (McManus et al., 2004).

Finally, we encountered some problems with model testing. The reader should realize, however, that the stability and change model aims at extracting extensive information from a relatively limited data source. In our research, the model served this goal appreciably well. By attempting to fit the initial research model to our data, we probably exhausted the possibilities of the method, unfortunately yielding an unstable solution. However, examining the revised initial model, the method was able to find a stable solution that explains the covariance structure in essentially the same way. To find a valid solution for a model that assumes mutual relationships between the change components of patient demands and burnout is most likely asking too much.

\section{Practical implications}

Because burnout among primary care physicians is rather common (Bakker, Schaufeli, \& Van Dierendonck, 2000; Soler et al., 2008) and because it is a chronic rather than a transient condition, as is illustrated by the high-stability coefficients found in the current study, physicians should be alert to burnout symptoms. Feelings of emotional exhaustion, tiredness, loss of sense of humor, irritability at work, a progressively cynical attitude to patients, inability to concentrate or listen to patients, a tendency to dehumanize patients, and suspicion and mistrust of others may all be symptoms of burnout.

Our study suggested that demanding patient contacts play an important role in the development of physician burnout. Nearly all primary care physicians have patients who engender a sense of frustration or dislike, often described as 'difficult'. Elder, Ricker, and Tobias (2006) described ways in which 'excellent' physicians (i.e., those were recommended by medical school primary care medicine faculty) dealt with such difficult patients. They grouped these strategies into three categories: (1) collaboration with the patient (e.g., priority setting, patient education), (2) empathy (e.g., emotional understanding and compassion), and (3) the appropriate use of power (e.g., setting boundaries and limitations). In addition, the physicians mentioned a set of strategies related to terminating relationships, when all else had failed. It seems that in all these cases, adequate doctor-patient communication is the key. Hence, dealing with difficult patients - and thus reducing patient demands - boils down to using effective communication skills. For an example of a continuing medical education programme to successfully increase these skills, see Levinson and Roter (1993).

\section{References}

Baltes, P. B., \& Baltes, M. M. (1990). Psychological perspectives on successful aging: The model of selective optimization with compensation. In P. B. Baltes \& M. M. Baltes (Eds.), Successful aging: Perspectives from the behavioral sciences (pp. 1-34). Cambridge: Cambridge University Press.

Bakker, A. B., Schaufeli, W. B., Sixma, H., Bosveld, W., \& Van Dierendonck, D. (2000). Patient demands, lack of reciprocity, and burnout: A five-year longitudinal study among general practitioners. Journal of Organizational Behavior, 21, 425-441. 
Bakker, A., Schaufeli, W. B., \& Van Dierendonck, D. (2000). Burnout: prevalentie, risicogroepen en risicofactoren [Burnout: Prevalence, groups at risk and risk factors]. In I. L. D. Houtman, W. B. Schaufeli, \& T. Taris (Eds.), Psychische vermoeidheid en werk: Cijfers, trends en analyses (pp. 65-82). Alphen a/d Rijn: Samsom.

Bargellini, A., Barbieri, A., Rovesti, S., Vivioli, R., Roncaglia, R., \& Borella, P. (2000). Relation between immune variables and burnout in a sample of physicians. Occupational and Environmental Medicine, 57, 453-457.

Burisch, M. (2002). A longitudinal study of burnout: The relative importance of dispositions and experiences. Work \& Stress, 16, 1-17.

Cole, D. A. (2006). Coping with longitudinal data in research on developmental psychopathology. International Journal of Behavioral Development, 30, 20-25.

Cole, D. A., Martin, N. C., \& Steiger, J. H. (2005). Empirical and conceptual problems with longitudinal trait-state models: Introducing a trait-state occasion model. Psychological Methods, 10, 3-20.

Conway, J. M. (2002). Method variance and method bias in industrial and organizational psychology. In S. G. Rogelberg (Ed.), Handbook of research methods in organizational and industrial psychology (pp. 344-365). Malden, NJ: Blackwell Publishers.

de Lange, A. H., Taris, T. W., Kompier, M., Houtman, I. L. D., \& Bongers, P. M. (2004). The relationships between work characteristics and mental health: Examining normal, reversed, and reciprocal relationships in a 4-wave study. Work and Stress, 18, 149-166.

Demerouti, E., Bakker, A. B., Vardakou, I., \& Kantas, A. (2003). The convergent validity of two burnout instruments: A multitrait-multimethod analysis. European Journal of Psychological Assessment, 19, 12-23.

DiMatteo, M. R., Sherbourne, C. D., Hays, R. D., Orddway, L., Kravits, R. L., \& McGlynn, E. A. (1993). Physicians' characteristics influence patients' adherence to medical treatment. Health Psychology, 12, 93-102.

Dollard, M. F., \& De Jonge, J. (2003). Measurement and methodological issues in work stress research. In M. F. Dollard, A. H. Winefield, \& H. R. Winefield (Eds.), Occupational stress in the service professions (pp. 76-102). London: Taylor \& Francis.

Dormann, C., Fay, D., Zapf, D., \& Frese, M. (2006). A state-trait analysis of job satisfaction: On the effects of core self-evaluation. Applied Psychology: An International Review, 55, 27-51.

Dormann, C., \& Zapf, D. (2002). Social stressors at work, irritation, and depressive symptoms: Accounting for unmeasured third variables in a multi-wave study. Journal of Occupational and Organizational Psychology, 75, 33-58.

Duncan-Jones, P., Fergusson, D. M., Ormel, J., \& Horwood, L. J. (1990). A model of stability and change in minor psychiatric symptoms. Results from three longitudinal studies. Psychological Medicine Monographs (No. 18) 3-28.

Elder, N., Ricker, R., \& Tobias, B. (2006). How respected physicians manage difficult patient encounters. Journal of the American Board of Family Medicine, 19, 533-541.

Epstein, R. M., Franks, P., Fiscella, K., Shields, C. G., Meldrum, S. C., Kravitz, R. L., et al. (2005). Measuring patient-centered communication in Patient-Physician consultations: Theoretical and practical issues. Social Science \& Medicine, 61, 1516-1528.

Freund, A. M., Baltes, P. B. (1998). Selection, optimization, and compensation as strategies of life management: Correlations with subjective indicators of successful aging. Psychology and Aging, 13, 531-543.

Goebring, C., Gallachi, M., Künze, B., \& Bovier, P. (2005). Psychosocial and professional characteristics of burnout in Swiss primary care practitioners: A cross-sectional study. Swiss Medical Weekly, 135, 101-108.

Goodman, J. S., \& Blum, T. C. (1996). Assessing the non-random sampling effects of subject attrition in longitudinal research. Journal of Management, 22, 627-652.

Gorgievski-Duijvesteijn, M. J., Bakker, A. B., Schaufeli, W. B., \& Van Der Heijden, P. G. M. (2005). Finances and wellbeing: A dynamic equilibrium model of resources. Journal of Occupational Health Psychology, 10, 210-224. 
Halbesleben, J., \& Buckley, M. R. (2004). Burnout in organizational life. Journal of Management, 30, 859-879.

Heckhausen, J., Worsch, C., \& Schulz, R. (2010). A motivational theory of life-span development. Psychological Review, 117, 32-60.

Heady, B., \& Wearing, A. (1989). Personality, life events, and subjective ell-being: Toward a dynamic equilibrium model. Journal of Personality and Social Psychology, 57, 731-739.

Hobbs, F. D. (1994). Fear of aggression at work among general practitioners who have suffered a previous episode of aggression. British Journal of General Practice, 44, 390-394.

Houkes, I., Winants, Y. H. W. M., \& Twellaar, M. (2008). Specific determinants of burnout among male and female practitioners: A cross-lagged panel analyses. Journal of Occupational and Organizational Psychology, 81, 249-276.

Hu, L. T., \& Bentler, P. M. (1999). Cutoff criteria for fit indices in covariance structure analyses: Conventional criteria versus new alternatives. Structural Equation Modeling, 6, 1-55.

Jonge, J. de, Dormann, C., Janssen, P. P. M., Dollard, M. F., Landeweerd, J. A., \& Nijhuis, F. J. N. (2001). Testing reciprocal relationships between job characteristics and psychological wellbeing: A cross-lagged structural equation model.Journal of Occupational and Organizational Psychology, 74, 29-46.

Jöreskog, K. G., \& Sörbom, D. (1989). LISREL 7, a guide to the program and applications (2nd ed.). Chicago, IL: SPSS Inc.

Keating, N. L., Green, D. C., Kao, A. C., Gazmarararian, J. A., Wu, V. Y., \& Cleary, P. D. (2002). How are patients' specific ambulatory care experiences related to trust, satisfaction and considering changing physicians. Journal of General Internal Medicine, 17, 29-39.

Leana, C. R., \& Barry, B. (2000). Stability and change as simultaneous experiences in organizational life. The Academy of Management Review, 25, 753-759.

Lee, R. T., \& Ashforth, B. E. (1996). A meta-analytic examination of the correlates of thee three dimensions of job burnout. Journal of Applied Psychology, 81, 123-133.

Leiter, M. P. (1993). Burnout as developmental process: Consideration of models. In W. B. Schaufeli, C. Maslach, \& T. Marek (Eds.), Professional burnout: Recent developments in theory and research (pp. 237-250). Washington, DC: Taylor and Francis.

Leiter, M. P., Durup, M. J. (1996). Work, home and in-between: A longitudinal study of spillover. Journal of Applied Behavioral Science, 32, 29-47.

Leone, S., Huibers, M., Knottnerus, J., \& Kant, I. J. (2008). The prognosis of burnout and prolonged fatigue in the working population: A comparison. Journal of Occupational and Environmental Medicine, 50, 1195-1201.

Levinson, W., \& Roter, D. (1993). The effects of two continuing medical education programs on communication skills of practicing primary care physicians. Journal of General Internal Medicine, 8, 318-324.

Lucas, R. E., \& Donnelan, M. B. (2007). How stable is happiness? Using the STARTS model to estimate the stability of life satisfaction. Journal of Research in Personality, 41, 1091-1098.

Lykken, D. T., \& Tellegen, A. (1996). Happiness is a stochastic phenomenon. Psychological Science, 7, 186-189.

Maslach, C., Jackson, S. E., \& Leiter, M. P. (1996). MBI: The Maslach Burnout Inventory: Manual. Palo Alto: Consulting Psychologists Press.

Maslach, C., Leiter, M. P., \& Schaufeli, W. B. (2008). Measuring burnout. In C. L. Cooper \& S. Cartwright (Eds.), The Oxford handbook of organizational well-being (pp. 86-108). Oxford: Oxford University Press.

Maslach, C., Schaufeli, W. B., \& Leiter, M. P. (2001). Job burnout. Annual Review of Psychology, 52, 397-422.

McManus, I. C., Keeling, A., \& Paice, E. (2004). Stress, burnout and doctor's attitudes to work are determined by personality and learning style. BMC Medicine, 29, 1-12.

McManus, I. C., Winder, B. C., \& Gordon, D. (2002). The causal links between stress and burnout in a longitudinal study of UK doctors: The Lancet, 359, 2089-2090. 
Mauthe, A. J., Boudreau, R. A., \& Lalumière, M. L. (2009). Physician burnout: A "Meta-O-Scopic" analysis. Poster presented at the 8th International Conference on Occupational Stress and Health. Puerto Rico.

Mechanic, D. (1970). Correlates of frustration among British general practitioners. Journal of Health and Social Behavior, 11, 87-104.

Myerson, S. (1991). Doctors' methods of dealing with "on going" stress in general practice. Medical Science Research, 19, 267-269.

Nes, R. B., Røysamb, E., Tambs, K., Harris, J. R., \& Reichborn-Kjellerud, T. (2006). Subjective well-being: Genetic and environmental contributions to stability and change. Psychological Medicine, 36, 1033-1042.

Nunnally, J. C., \& Bernstein, I. H. (1994). Psychometric theory (3 ${ }^{\text {rd }}$ ed.). New York: McGraw-Hill. Ormel, J., \& Schaufeli, W. B. (1991). Stability and change in psychological distress and their relationship with self-esteem and locus of control: A dynamic equilibrium model. Journal of Personality and Social Psychology, 60, 288-299.

Prins, J. T., Van Der Heijden, F. M. M. A., Hoekstra-Weebers, J. E. H. M., Bakker, A. B., Van de Wiel, H. B. M., Jacobs, B., et al. (2009). Burnout, engagement, and resident physicians' self-reported errors. Psychology, Health \& Medicine, 14, 654-666.

Piedmond, R. L., McCrae, R. R., Riemann, R., \& Angleiter, A. (2000). On the invalidity and validity of scales: Evidence from self-report and observer ratings in volunteer samples. Journal of Personality and Social Psychology, 78, 582-593.

Rout, U., Cooper, C. L., \& Rout, J. K. (1996). Job stress among British GPs: Predictors of job dissatisfaction and mental ill-health. Stress Medicine, 12, 155-166.

Rout, U., \& Rout, J. K. (1997). A comparative study on occupational stress, job satisfaction and mental health in British and Canadian family physicians. Psychology, Health \& Medicine, 2, 181-190.

Schaufeli, W. B. (2007). Burnout in health care. In P. Carayon (Ed.), Handbook of human factors and ergonomics in bealth care and patient safety (pp. 217-232). Mahway, NJ: Lawrence Erlbaum.

Schaufeli, W. B. Bakker, A. B., Schaap, C., Kladler, A., \& Hoogduin, C. A. L. (2001). On the clinical validity of the Maslach Burnout Inventory and the Burnout Measure. Psychology \& Health, 16, 565-582.

Schaufeli, W. B., \& Enzmann, D. (1998). The burnout companion to study and research: A critical analysis. London: Taylor \& Francis.

Schaufeli, W. B., \& Salanova, M. (2007). Efficacy or inefficacy, that's the question: Burnout and work engagement, and their relationship with efficacy beliefs. Anxiety, Stress \& Coping, 20, 177-196.

Schaufeli, W. B., \& Taris, T. W. (2005). The conceptualization and measurement of burnout: Common ground and worlds apart. Work \& Stress, 19, 356-262.

Schaufeli, W. B., \& Van Dierendonck, D. (2000). Handleiding van de Utrechtse Burnout Schaal (UBOS) [Manual Utrecht Burnout Scale]. Lisse: Swets Test Services.

Shanafelt, T., Bradley, K., Wipf, J., \& Back, A. (2002). Burnout and self-reported patient care in an internal medicine residency program. Annals of Internal Medicine, 136, 358-367.

Shirom, A., Nirel, N., \& Vinokur, A. D. (2006). Overload, autonomy and burnout as predictors of physicians' quality of care. Journal of Occupational Health Psychology, 11, 328-342.

Soler, J. S., Yaman, H., Esteva, M., Dobbs, F., Spiridonova Asenova, R., Katic, M., et al. (2008). Burnout in European family doctors: The EGPRN study. Family Practice, 25, 245-265.

Spector, P. E. (2006). Method variance in organizational research: Truth or urban legend? Organizational Research Methods, 2, 221-232.

Spickard, A., Gabbe, S. G., \& Christensen, J. F. (2002). Mid-career burnout in generalist and specialist physicians. Journal of the American Medical Association, 288, 1447-1450.

Tabery, J. (2007). Biometric and developmental gene-environment interaction: Looking back, moving forward. Development and Psychopathology, 19, 961-976. 
Taris, T., Le Blanc, P. M., Schaufeli, W. B., \& Schreurs, P. J. G. (2005). Are there causal relationships between the dimensions of the Maslach Burnout Inventory? A review and two longitudinal tests. Work \& Stress, 19, 238-256.

Toppinen-Tannerf, S., Kalimo, R., \& Mutanen, P. (2002). The process of burnout in white-collar and blue-collar jobs. Eight year prospective study of exhaustion. Journal of Organizational Behavior, 23, 255-270.

Tops, M., van Boksem, M., Wijers, A., van Duinen, H., den Boer, J., Meijman, Th., et al. (2006). The psychobiology of burnout: Are there two different syndromes. Neuropsychobiology, 55, 143-150.

Van Luijtelaar, G., Verbaak, M., van den Bunbt, M., Keijsers, G., \& Arns, M. (2010). EEG findings in burnout patients. Journal of Neuropsychiatry and Clinical Neuroscience, 22, 208-217.

Williams, E. S., Savage, G. T., \& Linzer, M. (2006). A proposed physician-patient cycle model. Stress \& Health, 22, 131-137.

Winefield, H. R. (2003). Work stress and its effects in General Practitioners. In M. F. Dollard, A. H. Winefield, \& H. R. Winefield (Eds.), Occupational stress in the service professions (pp. 191-212). London: Taylor \& Francis.

Received 27 March 2010; revised version received I December 2010

\section{Appendix}

\section{LISREL syntax of the model that is presented in Figure 2}

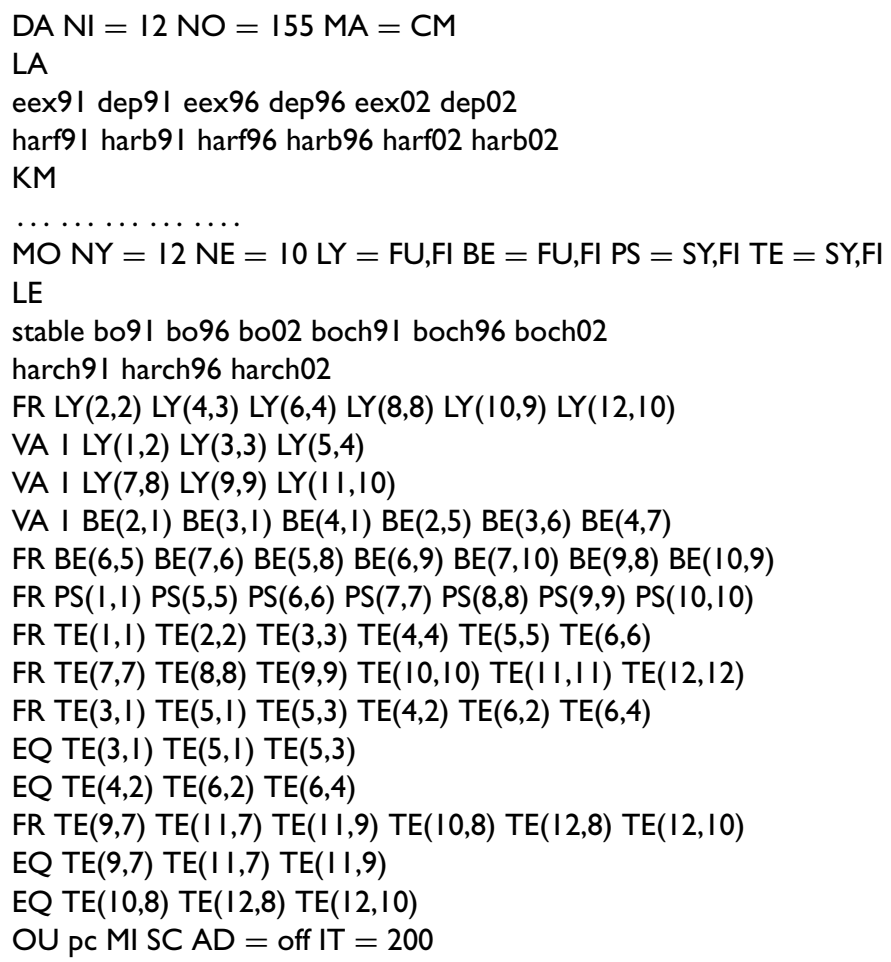

Note. eex = exhaustion; dep = deprsonalization; harf = frequency; harb = intensity; stable = stable burnout; bo = burnout; boch = burnout change; harch = demands. 